\title{
Morfogênese de milheto (Pennisetum americanum (L.) Leeke) em pastejo com terneiras, recebendo ou não suplementação 1
}

\author{
Pearl millet (Pennisetum americanum (L.) Leeke) morphogenesis under grazing \\ by heifers with or without supplementation
}

Edna Nunes Gonçalves ${ }^{1}$ Fernando Luiz Ferreira de Quadros ${ }^{2}$

RESUMO

\begin{abstract}
O experimento foi conduzido em área pertencente ao Departamento de Zootecnia da Universidade Federal de Santa Maria, região Central do Rio Grande do Sul, Brasil, para avaliar o efeito da freqüencia de desfolhação nas características morfogênicas de Pennisetum americanum quando utilizada ou não suplementação aos animais em pastejo, no periodo de 20/02 - 08/03/01 e 11/03 - 01/04/01. Foram utilizadas terneiras de corte em pastejo contínuo com lotação variável de forma a manter uma oferta de $12 \mathrm{~kg}$ de MS/ $100 \mathrm{~kg}$ de peso vivo. Para acompanhar a dinâmica de crescimento da pastagem, foi utilizada a técnica dos perfilhos marcados. O delineamento utilizado foi o completamente casualizado com 36 repetições. Os tratamentos adotados foram: pastagem de milheto sem suplemento; pastagem de milheto + $1 \%$ do peso vivo de polpa citrica moída e pastagem de milheto $+1 \%$ do peso vivo de milho moído. As variáveis da pastagem avaliadas foram taxa de surgimento de folhas (folha.dia ${ }^{-1}$.perfilho-1), taxa de elongação de folhas (mm.dia ${ }^{-1}$.perfilho ${ }^{-1}$ ), duração de vida das folhas (grausdia) e freqüencia de desfolhação (\% desfolha.dia ${ }^{-1}$.perfilho 1). Na média dos periodos, a freqüência de desfolhação não diferiu entre tratamentos, tendo em média, $23 \%$ de desfolha.dia ${ }^{-1}$.perfilho ${ }^{-1}$. Os tratamentos com suplementação apresentaram taxa de surgimento de folhas e de elongação de folhas em torno de 0,187 folhas.dia ${ }^{-1}$. perfilho-1 e $24 \mathrm{~mm}$. dia $^{-1}$.perfilho-1, respectivamente. Esses resultados foram superiores $(P<0,05)$ ao tratamento em que não era fornecido aos animais suplemento energético. A duração de vida das folhas dos tratamentos com uso de suplementos foi em média igual a 295,8 graus-dia, enquanto no tratamento sem suplemento este valor foi de 339 graus-dia. O uso da
\end{abstract}

suplementação com milho ou polpa cítrica para terneiras de corte não afetou a freqüência de desfolhação, condicionando a respostas positivas nas características morfogênicas. A seleção de forragem de melhor qualidade pode fazer com que ocorra a redução de folhas jovens, prejudicando o crescimento da planta.

Palavras-chave: duração de vida das folhas, freqüencia de desfolhação, taxa de elongação de folhas, taxa de surgimento de folhas.

\section{ABSTRACT}

The experiment was carried out in an area of the Department of Animal Science of the Universidade Federal de Santa Maria, Brazil to evaluate the effect of defoliation frequency in the morphogenic characteristics of Pennisetum americanum when used or not supplementation to the animals in grazing, during the period of 02/20 - 03/08/01 and 03/11 - 03/01/01. Beef heifers under continuous grazing were adjusted to a variable stocking rate in order to maintain an herbage allowance of $12 \mathrm{~kg}$ of DM.100 $\mathrm{kg}^{-1}$ of live weight. The technique of marked tillers was used to evaluate the growth dynamics of the pasture. The experimental design was completely randomized with 36 repetitions, to analyse the following treatments: Pearl Millet pasture without supplementation; Pearl Millet pasture + $1 \%$ of the live weight with citric pulp and Pearl Millet pasture $+1 \%$ of the live weight with corn. The pasture variables evaluated were: leaves appearance rate, leaves elongation rate, leaves lifespan and defoliation frequency. On the average of the two periods, defoliation frequency didn't differ between treatments, with an average of $23 \%$ of leaves defoliated.tiller ${ }^{-1} \cdot$ day $^{-1}$. Leaves appearance rate

\footnotetext{
${ }^{1}$ Parte da Dissertação do primeiro autor, financiada pela FAPERGS, apresentado como um dos requisitos para a obtenção do grau de Mestre em Zootecnia, ao Curso de Pós-graduação em Zootecnia, Universidade Federal de Santa Maria (UFSM).

${ }^{2}$ Engenheira Agrônoma, MSc. e-mail: edna.ng@bol.com.br.

${ }^{3}$ Engenheiro Agrônomo, Doutor, Professor, Departamento de Zootecnia, UFSM, Camobi. 97105-900, Santa Maria, RS, Brasil. Email:fquadros@ccr.ufsm.br. Autor para correspondência.
} 
$\left(0.187\right.$ leaves.tiller ${ }^{-1}$. day $\left.^{-1}\right)$ and leaves elongation rate $(24 \mathrm{~mm} /$ tiller/day) were higher $(P<0.05)$ when using supplement. Leaves lifespan of supplemented treatments was 295.8 degree-day. While in the treatment without supplementation, this value was of 339 degree-day. Use of the supplementation with corn or citric pulp for beef heifers didn't affect the defoliation frequency, conditioning positive responses in morphogenetic characteristics. Selection of better quality forage can cause the reduction of young leaves, damaging plant growth.

Key words: leaves lifespan, defoliation frequency, leaves elongation rate, leaves appearance rate.

\section{INTRODUÇ̃̃̃O}

A influência do pastejo sobre a vegetação é tão importante quanto o clima e o solo. Os herbívoros são elementos determinantes da estrutura da vegetação, especialmente em áreas de pastagens (SALA, 1988). Eles determinam modificações estruturais na vegetação que se expressa pela redução da superfície foliar afetando o fornecimento de assimilados necessários para sustentar as funções de crescimento de órgãos aéreos e subterrâneos e, eventualmente, o número de meristemas de crescimento (MAZZANTI, 1997).

O regime, ou padrão de desfolhação, é a variável de maior influência na resposta da planta ao pastejo. O padrão de desfolhação é definido pela intensidade (quantidade de material removido) e freqüência (número de vezes que a planta é desfolhada) em um dado período de tempo de desfolhação (Gillen et al. apud PIGATTO, 2001). Este padrão depende, primeiramente do método de pastejo: contínuo ou rotativo. No pastejo contínuo, relações estreitas entre variáveis de condição da pastagem, tais como, altura e densidade, e o comportamento de pastejo dos animais determinam a freqüência e a intensidade de desfolhação de plantas individuais (LEMAIRE, 1997). Ainda segundo este autor, quando nestas condições se utiliza a suplementação, através do fornecimento de ração, o consumo de forragem dos animais pode permanecer inalterado, aumentar ou diminuir, sendo que as respostas muitas vezes dependem da qualidade e da quantidade de forragem disponível.

Considerando-se a importância do milheto para a intensificação da produção pecuária no Rio Grande do Sul, com reconhecida capacidade de incrementos na produção forrageira e desempenho animal, a avaliação de aspectos do pastejo que interferem nas variáveis morfogênicas da planta forrageira, torna-se relevante como ferramenta para o processo de manejo e utilização das pastagens. Desta forma, o objetivo deste experimento foi avaliar o efeito da freqüência de desfolhação nas características morfogênicas de Pennisetum americanum quando utilizada ou não suplementação aos animais em pastejo.

\section{MATERIAL E MÉTODOS}

O trabalho foi conduzido em área pertencente ao Departamento de Zootecnia da Universidade Federal de Santa Maria, RS, Brasil, localizado a $29^{\circ} 43^{\prime} \mathrm{S}$ e $53^{\circ} 42^{\prime} \mathrm{W}$. O solo da área experimental é classificado como ARGISSOLO VERMELHO Distrófico Arênico (EMBRAPA, 1999). O clima da região é o Cfa (subtropical úmido), conforme classificação de Köppen (MORENO, 1961) com temperatura média anual de $19^{\circ} \mathrm{C}$. Os dados de temperatura máxima, mínima e média diária foram obtidos na estação meteorológica, do Departamento de Fitotecnia da Universidade Federal de Santa Maria, atingindo uma temperatura média, para o período de 20/02 a 01/04 de 2001 , de $24,4{ }^{\circ} \mathrm{C}$.

A área experimental utilizada foi de 2,0 hectares subdivididos em três piquetes de aproximadamente 0,7 ha cada, e cada piquete representou um tratamento. A pastagem foi estabelecida pelo método convencional, utilizando-se $35 \mathrm{~kg} / \mathrm{ha}$ de sementes de milheto, cv. Comum, semeadas a lanço, com valor cultural corrigido para $100 \%$. Os tratamentos utilizados foram: pastagem de milheto sem suplemento; pastagem de milheto + polpa cítrica moída e pastagem de milheto + milho moído. A quantidade de suplemento fornecido diariamente aos animais foi de $1,0 \%$ do peso vivo. A adubação de base aplicada na área experimental baseou-se na análise de solo, seguindo as recomendações da Comissão de Fertilidade do Solo RS/SC (SIQUEIRA et al., 1987), e correspondeu a $200 \mathrm{~kg} \cdot \mathrm{ha}^{-1}$ da fórmula 5-20-20 e $150 \mathrm{~kg} . \mathrm{ha}^{-1}$ de nitrogênio em cobertura, na forma de uréia, parcelado em duas aplicações (21/02 e 20/03 de 2001). Utilizaram-se terneiras mestiças com 100 dias de idade e peso inicial de $95 \mathrm{~kg}$. O método de pastejo foi o contínuo com lotação variável (MOTT \& LUCAS, 1952). Cada tratamento recebeu quatro terneiras testes e terneiros reguladores em número variável. $\mathrm{O}$ ajuste da carga animal foi a cada 21 dias, de acordo com a oferta de forragem pretendida ( $12 \mathrm{~kg}$ de MS. $\left.100 \mathrm{~kg}^{-1} \mathrm{de} \mathrm{PV}\right)$.

Em cada piquete foram marcados de forma aleatória 12 quadros de $0,25 \mathrm{~m}^{2}$, com três perfilhos identificados em cada quadro por anéis coloridos com um $\mathrm{mm}$ de espessura, totalizando 36 perfilhos por piquete, considerados como repetições dos tratamentos. As avaliações foram feitas diariamente e consistiram em medir o comprimento total das plantas e 
o comprimento individual das folhas que constituíam o perfilho. Foram formados dois períodos de avaliação (20/02 a 08/03 e 11/03 a 01/04 de 2001) em virtude do ajuste da carga animal ser feito a cada 21 dias. As variáveis determinadas foram: taxa de surgimento de folhas (folhas/dia/perfilho), obtida pela razão do número de folhas surgidas por perfilho pelo número de dias do período; taxa de elongação foliar ( $\mathrm{mm}$ de folha/dia/perfilho), obtida pela subtração do comprimento final de cada folha pelo seu comprimento inicial e dividindo-se pelo número de dias do período, obtendo-se um valor médio por perfilho (folhas que haviam sido desfolhadas, não foram consideradas para o cálculo da taxa de elongação); e duração de vida das folhas (graus-dia), obtida pelo produto do número de folhas verdes por perfilho pelo filocrono. Foram consideradas folhas verdes aquelas que estavam alongando, e aquelas que já se apresentavam totalmente expandidas, porém sem a ocorrência de senescência e desfolhação. Para a determinação do filocrono, foi calculado o acúmulo de temperatura (soma térmica acumulada, medida em graus-dia) tendo como temperatura base dez graus para o surgimento de uma nova folha. A cada valor de temperatura média do ar era subtraído o valor de dez graus, por esta ser a temperatura mínima requerida para o crescimento de espécies de estação quente (WESTPHALEN, 1975). A partir da razão entre o número de folhas surgidas no período, pela temperatura acumulada no período, foi calculado o filocrono médio para o milheto. A freqüência de desfolhação (\% desfolha/dia/perfilho), foi calculada a partir dos registros de desfolhações nas folhas verdes dos perfilhos marcados. Quando foi verificado que a(s) folha(s) tinha(m) sido pastejada(s), seu ápice foi marcado com corretor ortográfico para tornar possível a identificação de novos eventos de desfolhação nas avaliações seguintes.

As variáveis não apresentaram distribuição normal, homogeneidade dos erros experimentais e os piquetes não eram completamente casualisados, ferindo pressupostos da análise de variância univariada, o que justificou o uso de estatísticas não paramétricas. O delineamento experimental foi a inteiramente casualisado, e os perfilhos foram considerados como repetições. Para comparar os efeitos dos tratamentos, foram realizados testes de aleatorização através do programa MULTIV (PILLAR, 1997). A carga animal, a oferta real de forragem e a altura de perfilhos foram submetidos à analise de variância e, quando observada diferença significativa, utilizou-se o teste de Tukey, por meio do programa estatístico SAS (1996), ao nível mínimo de significância de 95\%.

\section{RESULTADOS E DISCUSSÃO}

A utilização de carga animal leve pode proporcionar aos animais a possibilidade de selecionar um alimento de melhor qualidade e maior digestibilidade, composto por folhas mais fotossinteticamente ativas (SHEEHY \& JOHNSON, 1988). O fato de o tratamento com utilização exclusiva de pastagem de milheto ter no primeiro período (20/ 02 a 08/03), uma carga animal 31\% inferior aos tratamentos que receberam suplemento, possibilitou uma maior oportunidade de seleção, em virtude da maior oferta de forragem, reduzindo a participação de folhas jovens no dossel (Tabela 1). Do total de folhas desfolhadas, $67 \%$ era compostos por folhas jovens, e nos demais tratamentos $46,4 \%$ de folhas jovens. Isso resultou a diminuição da taxa de elongação foliar média do tratamento sem suplemento (Tabela 2). Segundo BRISKE \& RICHARDS (1995), folhas maduras que com a desfolha permanecem na planta, apresentam uma taxa fotossintética reduzida numa extensão maior que a proporção de área foliar removida pela desfolha, conseqüência da menor capacidade fotossintética das folhas remanescentes.

Estudos demonstram existir uma grande variabilidade entre espécies tropicais quanto à taxa de elongação foliar. GOMIDE (1997) observou em Panicum maximum uma taxa de elongação foliar média de $85,5 \mathrm{~mm} \cdot \mathrm{dia}^{-1}$ para o período de estabelecimento e $69,9 \mathrm{~mm} . \mathrm{dia}^{-1}$ para o rebrote. CORSI

Tabela 1 - Carga animal, oferta real de forragem e altura de perfilhos de milheto em sistemas intensivos de utilização da pastagem. Valores médios. Santa Maria-RS, 2001.

\begin{tabular}{|c|c|c|c|}
\hline \multirow{2}{*}{ Tratamentos } & \multicolumn{2}{|c|}{ Períodos } & \multirow{2}{*}{ Média } \\
\hline & $16 / 02$ a $09 / 03$ & $10 / 03$ a $30 / 03$ & \\
\hline \multicolumn{4}{|c|}{ Carga animal (kg PV/ha) } \\
\hline Milheto & $2236,6 b$ & 1531,6 & $1884,1 \mathrm{~b}$ \\
\hline Milheto + Polpa & 2883,9 a & 1627,0 & $2255,5 \mathrm{a}$ \\
\hline Milheto + Milho & 2997,1 a & 1701,1 & 2349,1 a \\
\hline \multicolumn{4}{|c|}{ Oferta real $(\% \mathrm{PV})$} \\
\hline Milheto & $9,0 \mathrm{a}$ & $12,7 \mathrm{a}$ & $10,9 \mathrm{a}$ \\
\hline Milheto + Polpa & $7,2 \mathrm{~b}$ & $11,1 \mathrm{ab}$ & $9,2 \mathrm{~b}$ \\
\hline Milheto + Milho & $7,9 \mathrm{~b}$ & $10,2 \mathrm{~b}$ & $9,1 \mathrm{~b}$ \\
\hline \multicolumn{4}{|c|}{ Altura de perfilhos (cm) } \\
\hline Milheto & $43,6 \mathrm{a}$ & 29,2 & $36,4 \mathrm{a}$ \\
\hline Milheto + Polpa & $33,7 \mathrm{~b}$ & 24,8 & $29,3 \mathrm{~b}$ \\
\hline Milheto + Milho & $36,6 \mathrm{~b}$ & 25,3 & $31,0 \mathrm{~b}$ \\
\hline
\end{tabular}

Médias seguidas de letras distintas na coluna diferem estatisticamente entre si $(\mathrm{P}<0,05)$.

Ciência Rural, v. 33, n. 6, nov-dez, 2003. 
et al. (1994) registraram para Brachiaria brizantha cv. Marandu, taxa de elongação foliar de 12,3mm.dia ${ }^{-1}$.

No segundo período (11/03 a 01/04), os valores de taxa de elongação foliar foram bastante reduzidos, porém não houve diferença entre tratamentos. Este fato pode ser atribuído a este período coincidir com a diferenciação floral, na qual a planta exporta a maioria dos assimilados para o desenvolvimento da inflorescência, reduzindo a elongação foliar. Da mesma forma, houve uma redução na carga animal neste período, sem haver diferença entre os tratamentos, resultando em uma freqüência de desfolhação menor nos tratamentos suplementados. Isto devido à substituição da matéria seca da pastagem pela matéria seca do suplemento, em virtude da queda na qualidade da pastagem pelo avanço do estádio de desenvolvimento das plantas. De acordo com REIS et al. (1997), a suplementação de animais em pastejo é realizada com o objetivo de corrigir a deficiência de nutrientes, aumentar a capacidade de suporte, bem como auxiliar no manejo das pastagens. Quando um suplemento é fornecido, o consumo de forragem dos animais mantidos em pastagens pode permanecer inalterado, aumentar ou diminuir, sendo que as respostas muitas vezes, dependem da pastagem e da quantidade de suplemento oferecido. Segundo HODGSON (1990), há poucas situações nas quais o concentrado age realmente como suplemento, ou seja, é consumido sem acarretar diminuição no consumo de forragem.

Para a taxa de surgimento foliar, o tratamento sem suplemento foi sempre inferior aos tratamentos suplementados. Isto significa um maior intervalo de surgimento de folhas alcançando em média 7,3 dias para o surgimento de uma nova folha no perfilho, cerca de dois dias a mais que os tratamentos suplementados (Tabela 2). CORSI et al. (1994) obtiveram para alguns cultivares de $\boldsymbol{P}$. maximum taxa de surgimento foliar em torno de 0,192 folhas/dia/ perfilho, e para B. brizantha cv. Marandu 0,15 a 0,19 folhas/dia/perfilho. Enquanto ALMEIDA et al. (1997) encontraram para Pennisetum purpureum cv. Mott, taxa de surgimento foliar de 0,13 a 0,17 folhas/dia/ perfilho. Esses valores estão muito próximos aos encontrados para o tratamento sem suplemento $(0,138$ folhas/dia/perfilho) e para os tratamentos com suplementação $(0,186$ folhas/dia/perfilho).

Um dos fatores que pode influenciar a taxa de surgimento foliar é a altura do dossel da pastagem, devido ao aumento do comprimento da bainha das folhas sucessivas de gramíneas cespitosas, havendo uma maior demora no surgimento das folhas acima do pseudocolmo (LEMAIRE \& CHAPMAN, 1996). Os dados de altura média dos perfilhos de milheto confirmam esta citação e o tratamento não suplementado apresentou uma altura média de perfilhos de $36,4 \mathrm{~cm}$, enquanto que os demais tratamentos atingiram em torno de $30,2 \mathrm{~cm}$, em média (Tabela 1).

A importância de se conhecer a taxa de surgimento foliar reside no fato de que o acúmulo de massa numa haste é decorrente do acúmulo de fitômeros (unidade básica do perfilho, composta por nó, entrenó, folha e gemas axilares) e do seu

Tabela 2 - Taxa de elongação foliar, freqüência de desfolhação, taxa de surgimento foliar, intervalo de surgimento de folhas, filocrono, número de folhas verdes e duração de vida das folhas de $\boldsymbol{P}$. americanum em dois períodos de avaliação, com e sem o uso de suplementação. Valores médios. Santa Maria, RS-2001.

\begin{tabular}{|c|c|c|c|}
\hline \multirow{2}{*}{ Períodos } & \multicolumn{3}{|c|}{ Tratamentos } \\
\hline & $20 / 02$ a $08 / 03$ & $11 / 03$ a $01 / 04$ & Médias \\
\hline & \multicolumn{3}{|c|}{ Taxa de elongação (mm/dia/perfilho) } \\
\hline Milheto & $27,5 \mathrm{~b}$ & 17,7 & $22,6 b$ \\
\hline Milheto + Polpa & $30,4 \mathrm{a}$ & 19,0 & $24,7 a$ \\
\hline \multirow[t]{2}{*}{ Milheto + Milho } & $33,2 \mathrm{a}$ & 17,1 & $25,2 a$ \\
\hline & \multicolumn{3}{|c|}{$\begin{array}{l}\text { Freqüência de desfolhação } \\
\text { (\%desfolha/dia/perfilho) }\end{array}$} \\
\hline Milheto & $17,2 \mathrm{~b}$ & $28,1 \mathrm{a}$ & 22,7 \\
\hline Milheto + Polpa & $25,7 \mathrm{a}$ & $21,4 \mathrm{~b}$ & 23,6 \\
\hline \multirow[t]{2}{*}{ Milheto + Milho } & $22,6 \mathrm{a}$ & $22,8 \mathrm{~b}$ & 22,7 \\
\hline & \multicolumn{3}{|c|}{ Taxa de surgimento (folhas/dia/perfilho) } \\
\hline Milheto & $0,126 \mathrm{~b}$ & $0,150 \mathrm{~b}$ & $0,138 b$ \\
\hline Milheto + Polpa & $0,197 \mathrm{a}$ & $0,171 \mathrm{a}$ & $0,184 a$ \\
\hline \multirow[t]{2}{*}{ Milheto + Milho } & $0,206 \mathrm{a}$ & $0,172 \mathrm{a}$ & $0,189 a$ \\
\hline & \multicolumn{3}{|c|}{ Intervalo de surgimento (dias) } \\
\hline Milheto & 7,9 a & $6,7 \mathrm{a}$ & $7,3 a$ \\
\hline Milheto + Polpa & $5,1 \mathrm{~b}$ & $5,8 \mathrm{~b}$ & $5,5 b$ \\
\hline \multirow[t]{2}{*}{ Milheto + Milho } & $4,9 \mathrm{~b}$ & $5,8 \mathrm{~b}$ & $5,4 b$ \\
\hline & \multicolumn{3}{|c|}{ Filocrono (graus-dia) } \\
\hline Milheto & $86,5 \mathrm{a}$ & $76,5 \mathrm{a}$ & $81,5 a$ \\
\hline Milheto + Polpa & $71,0 \mathrm{~b}$ & $63,2 \mathrm{~b}$ & $67,1 \mathrm{~b}$ \\
\hline \multirow[t]{2}{*}{ Milheto + Milho } & $73,7 \mathrm{~b}$ & $56,3 \mathrm{~b}$ & $65,0 \mathrm{~b}$ \\
\hline & \multicolumn{3}{|c|}{ Número de folhas verdes } \\
\hline Milheto & 4,3 & 4,0 & 4,2 \\
\hline Milheto + Polpa & 4,3 & 4,6 & 4,5 \\
\hline \multirow[t]{2}{*}{ Milheto + Milho } & 4,3 & 4,8 & 4,6 \\
\hline & \multicolumn{3}{|c|}{ Duração de vida (graus-dia) } \\
\hline Milheto & $372,0 \mathrm{a}$ & 306,0 a & $339,0 a$ \\
\hline Milheto + Polpa & $305,3 \mathrm{~b}$ & $290,7 \mathrm{ab}$ & $298,0 \mathrm{~b}$ \\
\hline Milheto + Milho & $316,9 \mathrm{~b}$ & $298,0 \mathrm{~b}$ & $293,6 b$ \\
\hline
\end{tabular}

Médias seguidas de letras distintas na coluna diferem estatisticamente entre si $(\mathrm{P}<0,05)$. 
desenvolvimento individual (KLEPPER et al., 1982). Outra forma de expressar a taxa de surgimento foliar é através do filocrono, que determina o tempo necessário, em acúmulo de graus-dia, para o surgimento de uma nova folha no perfilho. O uso do conceito de graus-dia permite integrar ao calendário humano uma unidade de tempo às quais as plantas são sensíveis independente das temperaturas a elas impostas a cada dia. Desta forma, os tratamentos suplementados apresentaram, em média, filocronos inferiores ao tratamento sem suplemento, que significa que foi necessário menor acúmulo de graus-dia para o surgimento de uma nova folha nestes tratamentos (Tabela 2).

O número de folhas verdes por perfilho é uma característica genotípica e relativamente constante (NABINGER, 1996). Deste modo, independente de tratamento o numero de folhas verdes por perfilho foi bastante similar, (média de 4,4, Tabela 2). Para B. decumbens foram encontrados valores de 5,0 a 7,0 folhas/perfilho (CORSI et al., 1994), para P. maximum 4,6 folhas/perfilho (PINTO et al., 1994) e para $\boldsymbol{P}$. purpureum de 5,4 a 6,8 folhas/perfilho (ALMEIDA et al., 1997).

Sendo a duração de vida igual ao produto do número de folhas verdes por perfilho pelo filocrono, a maior média foi do tratamento não suplementado, devido principalmente à necessidade de um maior acúmulo de temperatura para o surgimento de uma nova folha no perfilho. Os tratamentos suplementados com polpa cítrica e milho tiveram uma duração de vida média de 295,8 grausdia, enquanto o tratamento não suplementado atingiu seu potencial de rendimento, apenas quando completou 339 graus-dia. O que significa que este último permaneceu durante um maior tempo térmico com uma quantidade máxima de material verde sem que houvesse senescência. Em capim elefante anão, ALMEIDA et al. (1997) observaram 9,2 folhas vivas por perfilho, que, para um filocrono de 85 graus-dia, representou uma DV de 782 graus-dia.

\section{CONCLUSÕES}

O uso da suplementação com milho ou polpa cítrica para terneiras de corte proporcionou incrementos na carga animal, mas não afetou a freqüência de desfolhação, condicionando a respostas positivas nas características morfogênicas.

A seleção de forragem de melhor qualidade, em virtude da utilização de carga animal baixa pode provocar a redução de folhas com maior eficiência fotossintética, prejudicando o crescimento da planta.

\section{REFERÊNCIAS BIBLIOGRÁFICAS}

ALMEIDA, E.X.; SETELICH, E.A.; MARASCHIN, G.E. Oferta de forragem e variáveis morfogênicas em capim elefante anão cv. Mott. In: REUNIÃO ANUAL DA SOCIEDADE BRASILEIRA DE ZOOTECNIA, 34., 1997, Juiz de Fora. Anais... Juiz de Fora : Sociedade Brasileira de Zootecnia, 1997. p.240-242.

BRISKE, D.D.; RICHARDS, J. Plant responses to defoliation: a physiologic, morphologic and demographic evaluation. In: BEDUNAH, J.; SOSEBEE, R.E. (Eds). Journal of Range Management, Denver, 1995. p.653-709.

CORSI, M. et al. Bases para o estabelecimento do manejo de pastagens de braquiária. In: SIMPOSIO SOBRE MANEJO DE PASTAGENS, 1994, Piracicaba. Anais... Piracicaba : ESALQUSP, 1994. p.249-266.

EMBRAPA. Centro Nacional de Pesquisa Agropecuária. Sistema brasileiro de classificação de solos. Rio de Janeiro : EMBRAPA, 1999. 412p.

GOMIDE, C.A.de M. Morfogênese e análise de crescimento de cultivares de Panicum maximum (Jacq.). 1997. 53f. Dissertação (Mestrado em Zootecnia) Universidade Federal de Viçosa.

HODGSON, J. Grazing management: Science into practice. Longman scientific and technical. London : Longman Group, UK, 1990. p.203.

KLEPPER, B.; RICKMAN, R.W.; PETERSON, C.M. Quantitative characterization of vegetative development in small cereal grains. Journal Agronomy, v.74, p.789-792, 1982 .

LEMAIRE, G.; CHAPMAN, D. Tissue flows in grazed plants communities. In: HODGSON, J.; ILlIUS, A.W. (Eds). The ecology and management of grazing systems. Wallingford, UK : Cab International, 1996. p.3-36.

LEMAIRE, G. The physiology of grass growth under grazing: Tissue turn-over. In: SIMPOSIO INTERNACIONAL SOBRE PRODUÇÃO ANIMAL EM PASTEJO, 1997, Viçosa. Anais... Viçosa :UFV, 1997. p.117-144.

MAZZANTI, A. Adaptación de especies forrajeras a la defoliación. In: SIMPOSIO SOBRE AVALIAÇÃO DE PASTAGENS COM ANIMAIS, 1997, Maringá. Anais... Maringá : UEM - Cooper, 1997. p.5-84.

Moreno, J.A. Clima do Rio Grande do Sul. Porto Alegre : Secretaria da Agricultura, 1961. 41p.

MOTT, G.O.; LUCAS, H.L. The design conduct and interpretation of grazing trials on cultivated and improved pastures. In: INTERNATIONAL GRASSLAND CONGRESS, 6., 1952, Pensylvania. Proceedings... Pensylvania : International Grassland Congress, 1952. p.1380-1395.

NABINGER, C. Princípios de exploração intensiva de pastagens. In: PEIXOTO, A. M.; MOURA, J.C.; FARIA, V.P. (Eds). PRODUÇÃO DE BOVINOS A PASTO, 13., 1996, Piracicaba, SP. Anais... Piracicaba: , FEALQ. 
Simpósio sobre Manejo da Pastagem, 1996. p.15-96.

PIGATTO, A.G.S. Dinâmica da vegetação e do crescimento de Lolium multiflorum Lam. e Paspalum urvillei Steud., em área de várzea, sob pastejo. 2001. 100f. Dissertação (Mestrado em Zootecnia) - Universidade Federal de Santa Maria, Santa Maria.

PILLAR,V.D.P. Multivariate exploratory analysis and randomization testing with MULTIV. Coenoses, v.12, p.145-148, 1997.

PINTO, J.C. et al. Crescimento de folhas de gramíneas forrageiras tropicais, cultivadas em vasos, com duas doses de nitrogênio. Sociedade Brasileira de Zootecnia, v.23, n.3, p.327-332, 1994.

REIS, R.A.; RODRIGUES, L.R.A.; PEREIRA, J.R.A. A suplementação como estratégia de manejo da pastagem. In: PEIXOTO, A.M.; MORA, J.C.; FARIA, V.P. (Eds). Produção de bovinos a pasto. Piracicaba : FEALQ, 1997. p.123-150.

SALA, O.E. Effecto del pastoreo sobre la estructura de la vegatacion a distintas escalas de tiempo y espacio. Revista Argentina de Producción Animal, v.8, p.6-7, 1988.

SAS INSTITUTE. SAS/STAT. User's guide: statistics. Version 6. 4. ed. Cary, 1996. V.2.

SHEEHY, J.E.; JOHSON, I.R. Physiological models of grass growth. In: JONES, M.B.; LAZENBY, A. The grass crop: the physiological basis of production. London : Chapman and Hall, 1988. p.243-275.

SIQUEIRA, J.F. de et al. Recomendação de Adubação e calagem para os estados do Rio Grande do Sul e Santa Catarina. Passo Fundo : EMBRAPA - CNPT, 1987. $100 \mathrm{p}$.

WESTPHALEN, S.L. Forrageiras de clima tropical e subtropical - Zoneamento climático. In: ZONEAMENTO AGRÍCOLA, ESTUDOS BÁSICOS. 2., 1975, Porto Alegre. Anais... Porto Alegre : Governo do Estado do Rio Grande do Sul, 1975. p.26-32. 